\title{
ARTICLE
}

Cite this: DOI: $10.1039 /$ xoxxooooox

\section{The Kinetics and Mechanism of the Oxidation of Pyruvate ion by Hypochlorous Acid}

\author{
Mónika Galajda, ${ }^{a}$ Tímea Fodor, ${ }^{b}$ Mihály Purgel ${ }^{a}$ and István Fábián ${ }^{* b}$
}

Received ooth January 2012, Accepted ooth January 2012

DOI: $10.1039 /$ xoxxooooox

www.rsc.org/

\begin{abstract}
The oxidation of pyruvic acid by hypochlorous acid was studied in the $\mathrm{pH} 1.0-11.0$ range. The main path in the redox process is the reaction between the pyruvate ion and $\mathrm{HOCl}$. It was shown that the reaction is second order in both reactants and $k_{\mathrm{HOCl}}=2.14 \pm 0.02 \mathrm{M}^{-1} \mathrm{~s}^{-1}\left(I=1.0 \mathrm{M}\left(\mathrm{NaClO}_{4}\right), T=25.0^{\circ} \mathrm{C}\right)$

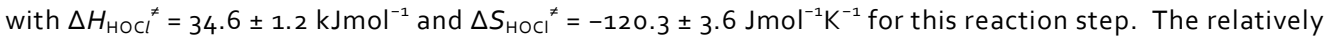
large negative entropy of activation is consistent with an $\mathrm{O}$ atom-transfer mechanism. DFT calculations support this conclusion by predicting a concerted rearrangement of the activated complex which includes the reactants and the solvent water molecule. It was also confirmed that the hydration of pyruvic acid has significant contribution to the observed kinetic features under acidic condition. The hydration reaction is a proton catalyzed process and the pseudo-first order rate constant can be interpreted by considering theprotolytic and hydration equilibria of pyruvic acid. The rate constants were determined for the non-catalytic and the proton catalyzed path: $k_{\mathrm{ho}}=0.24 \pm 0.01 \mathrm{~s}^{-1}$ and $k_{\mathrm{h} 1}=5.5 \pm$ $0.2 \mathrm{M}^{-1} \mathrm{~s}^{-1}$.
\end{abstract}

\section{Introduction}

Disinfection processes, environmental and biochemical relevance have generated great interest in the redox chemistry of oxychlorine species. ${ }^{1-15}$ In our ongoing studies we use organic substrates as initiators to generate chlorine dioxide from chlorite ion. In such systems, initial oxidation of the substrate by chlorite ion leads to the formation of intermediate species from both reactants and the final products are generated in subsequent reactions of the intermediates. Recently, we have observed very complex kinetic patterns in the chlorite ion lactic acid system. Preliminary experimental results indicate the formation of chlorine dioxide and chlorate ion as final products in variable concentration ratios depending on the $\mathrm{pH}$, the concentrations and the concentration ratios of the reactants. Pyruvate ion and hypochlorous acid are formed as intermediates in the reaction and expected to play significant role in this system. ${ }^{16}$ The main objective of this work is to explore the kinetics and mechanism of the redox reaction between these two species.

In a broader context, the results also bear relevance on the redox chemistry of the reactants. The reactions of pyruvate ion have extensively been studied in recent years due to the specific role of this species in various biological redox processes. ${ }^{17-20}$ Furthermore, the simplicity of the molecule allows modeling the oxidation of organic substrates in the presence of various oxidants. $^{21-26}$ Pyruvic acid is a simple substrate with a carbonyl group next to a carboxylic group. As such, its oxidation in aqueous solution may yield either acetaldehyde or acetic acid. With strong oxidants, such as the hypochlorous acid, the formation of the latter product is expected.
Hypochlorous acid is considered to be a strong disinfecting agent which is broadly used in water treatment technologies ${ }^{27-32}$ but also plays an important role in oxidative stress in vivo systems. ${ }^{33-40}$ Due to its outstanding oxidative power, this species can significantly alter the activities and availabilities of biomolecules. Hypochlorous acid may act either as a chlorinating agent or as an O-donor oxidant leading to the formation of very different types of products. It is a key issue how these alternative reaction paths occur under environmental and biological conditions. A survey of the literature reveals that with a few exceptions ${ }^{29}, 31,41-45$ only limited reliable information is available on the intimate details of the oxidation reactions of hypochlorous acid.

In this study we provide a thorough account on the kinetics of the title reaction and elaborate the mechanistic details also using DFT calculations. The results are expected to contribute to better understanding the redox chemistry of the reactants, in particular, the features of $\mathrm{HOCl}$ as an O-donor oxidant.

\section{Experimental}

\section{Materials}

Chloride ion free sodium hypochlorite was prepared similarly to a method described earlier. ${ }^{46,47}$ Gaseous chlorine was bubbled into an aqueous slurry of yellow $\mathrm{HgO}$ at room temperature. The oxidant was used in adequate excess over $\mathrm{Cl}_{2}$ and the slurry was intensively stirred for 3 hours after administering chlorine gas in order to drive the oxidation process to completion. 


$$
\mathrm{HgO}+2 \mathrm{Cl}_{2}+\mathrm{H}_{2} \mathrm{O}=2 \mathrm{HOCl}+\mathrm{Hg}_{2} \mathrm{Cl}_{2}
$$

Unoxidized chloride was converted into $\mathrm{HgCl}_{2}$ and the mixture of the $\mathrm{HOCl} / \mathrm{HgCl}_{2} / \mathrm{HgO}$ slurry was distilled under reduced pressure and argon atmosphere into a $0.4 \mathrm{M} \mathrm{NaOH}$ solution.

$$
\begin{aligned}
& 2 \mathrm{HOCl}=\mathrm{Cl}_{2} \mathrm{O}+\mathrm{H}_{2} \mathrm{O} \\
& \mathrm{Cl}_{2} \mathrm{O}+2 \mathrm{NaOH}=2 \mathrm{NaOCl}+\mathrm{H}_{2} \mathrm{O}
\end{aligned}
$$

The stock solutions of $\mathrm{NaOCl}$ were stored at $5{ }^{\circ} \mathrm{C}$ in the dark and were standardized by iodometric titration before use. ${ }^{48}$ The concentration of excess $\mathrm{NaOH}$ in the stock solution was determined by $\mathrm{pH}$ titration with standard $\mathrm{HClO}_{4}$.

Other reagents (Na-pyrAldrich, KI Reanal, $\mathrm{NaOH}$ Aldrich) were of reagent grade quality and used without further purification. Samples were prepared using doubly deionized and ultrafiltered water obtained from a MILLI-Q RG (Millipore) water purification system.

The kinetic measurements were made at $25 \pm 0.1{ }^{\circ} \mathrm{C}$ and 1.0 $M$ ionic strength set with $\mathrm{NaClO}_{4}$ prepared from $\mathrm{HClO}_{4}$ (Reanal) and $\mathrm{Na}_{2} \mathrm{CO}_{3}$ (Reanal). ${ }^{49}$ The concentration of $\mathrm{NaClO}_{4}$ was determined by drying a known volume of the stock solution in an oven at $120{ }^{\circ} \mathrm{C}$ and weighing the mass of the recovered solid.The $\mathrm{pH}$ was adjusted with perchloric acid or $\mathrm{NaOH}$ solutions.

\section{Instruments and methods}

Iodometric and $\mathrm{pH}$ titrations were made with a Metrohm 721 NET Titrino system equipped with Metrohm 6.0451.100 combination platinum and Metrohm 6.0262.100 combination glass electrodes, respectively. The $\mathrm{pH}$ was measured within \pm 0.003 unit, and it is defined as $-\log \left[\mathrm{H}^{+}\right]$in this paper.

Spectrophotometric measurements were made with a Hewlett-Packard 8543 UV/VIS diode array spectrophotometer (equipped with a built-in magnetic stirrer) using different illumination protocols to explore the possibility of unwanted photoreactions. ${ }^{50}$ Photochemical interference was not observed in this system. Measurements were made in stoppered quartz cells of $10 \mathrm{~mm}$ light path. The temperature of the cell was controlled by a built-in thermoelectric Peltier device.

Conventional fast kinetic measurements were performed in aqueous solution under pseudo-first-order conditions with an Applied Photophysics DX-17MV sequential stopped-flow instrument using $10 \mathrm{~mm}$ optical path at 220 and $325 \mathrm{~nm}$. Pseudo-first order rate constants were obtained from the average of five replicate kinetic runs. Quenched stopped-flow measurements were made with a HI-TECH RQF-63 instrument. Data fitting was made with the program packages SCIENTIST $^{51}$ and ORIGIN ${ }^{52}$ using non-linear least-squares routines.

${ }^{1} \mathrm{H}$ NMR spectra were recorded by using a Bruker DRX 400 $(9.4 \mathrm{~T}) \mathrm{NMR}$ spectrometer equipped with a Bruker VT-1000 thermocontroller and a BB inverse $z$ gradient probe $(5 \mathrm{~mm})$. Pyruvic acid solutions $(0.5 \mathrm{M})$ were prepared in $\mathrm{H}_{2} \mathrm{O}\left(\mathrm{D}_{2} \mathrm{O}\right.$ was added to the samples in capillary). The chemical shifts are reported in ppm, using DSS (4,4-dimethyl-4-silapentane-1sulfonic acid) as an external standard. The spectra were analyzed with the Bruker WinNMR software package.

\section{DFT calculations}

DFT calculations were performed with $\mathrm{B} 3 \mathrm{LYP}^{53}$ and $\mathrm{M}^{5} 6^{54}$ hybrid functionals. In addition, two different Pople-type basis sets have been used: the $6-31+\mathrm{G}(\mathrm{d}, \mathrm{p})$ double- $\zeta$ and the 6 $311+G(d, p)$ triple- $\zeta$ basis sets with one set of diffuse and polarization functions. ${ }^{55}$ Geometryoptimizations were carried out using the polarizable continuum model (PCM) to account for solvent effects. For PCM calculations, we used Gaussian 09's default Integral Equation Formalism variant (IEFPCM) PCM model. ${ }^{56}, 57$ The transition states were optimized by means of the synchronous transit-guided quasi-Newton method. ${ }^{58,59}$ The lack of imaginary frequencies in vibrational spectral calculations were taken to verify that the calculated stationary points on the potential energy surfaces (PES) represented true minima as opposed to transition states (TS). The reactants and products are obtained from intrinsic reaction coordinate (IRC) calculations. The relative energies are Gibbs free energies obtained by frequency analysis at 298 K.The calculations were performed with the Gaussian 09 software package. $^{60}$

\section{Results and discussion}

\section{Stoichiometric experiments}

The stoichiometry of the reaction was studied at different concentration ratios of pyruvate ion and hypochlorous acid. The reactants were mixed and the spectra were recorded after completion of the reaction. The composition of the spent reaction mixture was calculated by using the characteristic spectra for each major component (Fig.S1, ESI $\dagger$ ). Acidic reaction mixtures were made alkaline before recording their spectra in order to enhance the sensitivity of the measurements. The stoichiometry was found invariably $1: 1$ for pyruvate ion and $\mathrm{HOCl}$ over the $\mathrm{pH} 2-10$ range (Table $\mathrm{S} 1$ in ESI $\dagger$ ). Thus, the overall reaction can be written as follows:

$$
\mathrm{CH}_{3} \mathrm{COCOOH}+\mathrm{HOCl}=\mathrm{CH}_{3} \mathrm{COOH}+\mathrm{CO}_{2}+\mathrm{H}_{2} \mathrm{O}+\mathrm{Cl}^{-}
$$

\section{Kinetic studies in the $\mathrm{pH} 4-12$ region}

Under alkaline conditions, the reaction was studied in the excess of the oxidant using standard spectrophotometric method. Simple first-order kinetic traces were observed by monitoring the absorbance decay at the characteristic absorbance band of $\mathrm{OCl}^{-}\left(\lambda_{\max }=292 \mathrm{~nm}\right) .{ }^{47}$ The pseudo-firstorder rate constant is a linear function of the hypochlorous acid concentration with zero intercept. These results confirm an overall second order rate law for the reactants.

$$
v=-\frac{\mathrm{d}[\mathrm{Cl}(\mathrm{I})]}{\mathrm{d} t}=k_{\mathrm{obs}}[\mathrm{Cl}(\mathrm{I})][\mathrm{PYR}]
$$

where $k_{\mathrm{obs}}$ is a $\mathrm{pH}$ dependent pseudo second order rate constant and $[\mathrm{Cl}(\mathrm{I})]$ and $[\mathrm{PYR}]$ stand for the sum of the concentrations of the acidic and basic forms of the corresponding reactants.

The reaction became faster by decreasing the $\mathrm{pH}$ and eventually it could not be monitored spectrophotometrically because the spectral effect vanished. The protolytic equilibrium of the oxidant is shifted toward the acidic form under $\mathrm{pH} 7.0$ and $\mathrm{HOCl}$ has relatively small absorbance compared to hypochlorite ion. Thus, the change was not measurable. An attempt was made to use pyruvate ion in 
excess and to monitor the reaction at lower wavelengths. However, due to the large absorbance of pyruvate ion, these attempts were not successful. In addition, when the reactant concentrations were increased significantly, the formation of carbon dioxide led to the evolution of small bubbles in the cell which interfered with spectrophotometric monitoring of the reaction.

In order to avoid the noted technical problems, the reaction was studied by using the quenched stopped flow method in the neutral - slightly acidic region. This kinetic technique is more laborious than the standard stopped-flow method and it has sporadically been used for studying inorganic reactions. ${ }^{61,62}$ The method is based on immediate chemical quenching of the studied reaction, thus it requires the use of a quenching agent, which is capable to remove the reactant(s) instantaneously. The quenching process should be much faster than the reaction studied and should not trigger unknown side reactions. Once the reaction is stopped, the reaction mixture can easily be analyzed for the products of either the main reaction and/or the quenching reaction. In the latter case, the concentration of a species formed in equivalent amount form the reactant is determined at a given reaction time. In other words, the amounts of unreacted reactants and product can be determined at various reaction times.

The shortest cumulative dead-time of the HI-TECH RQF-63 unit used in this study is below $4 \mathrm{~ms}$. This time is required to start up a reaction and subsequently freeze it by administering an appropriate quenching agent. Therefore, the instrument can conveniently be used for monitoring reactions with pseudo first order rate constants up to $100 \mathrm{~s}^{-1}$. Pyruvate ion was used in large excess in the quenched stopped-flow experiments and 0.5 $\mathrm{M} \mathrm{NaI}$ solution was used as quenching agent. Iodide ion instantaneously reduced hypochlorous acid to chloride ion and an equivalent amount of iodine formed. Kinetic traces were recorded by stopping the oxidation reaction at various reaction times and determining the amount of iodine formed by standard potentiometric titration with thiosulfate solution. A representative kinetic curve is plotted in Fig. 1.

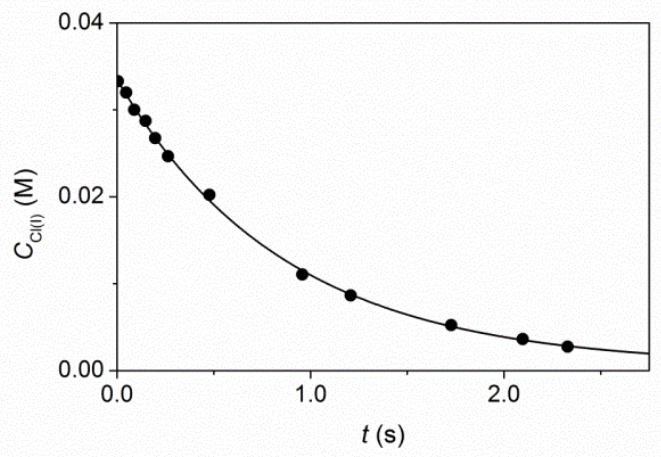

Fig. 1Typical kinetic trace obtained by the quenched stoppedflow method. $C_{\mathrm{PYR}}{ }^{0}=0.500 \mathrm{M}, C_{\mathrm{HOCl}}{ }^{0}=3.29 \times 10^{-2} \mathrm{M}, \mathrm{pH}=3.88$, $I=1.0 \mathrm{M}\left(\mathrm{NaClO}_{4}\right), T=25.0^{\circ} \mathrm{C}$. Quenching agent: $0.500 \mathrm{M} \mathrm{Nal}$.

The pseudo-second-order rate constant is shown as a function of $\mathrm{pH}$ in Fig. 2. The results obtained from the regular spectrophotometric and the quenched stopped-flow experiments complement each other remarkably well.

Pyruvate ion is the dominant form of the substrate above $\mathrm{pH}$ 4.0, thus the characteristic $\mathrm{pH}$ dependence of the rate constant can be interpreted by considering the fast protolytic equilibrium of hypochlorous acid (eq. 6).

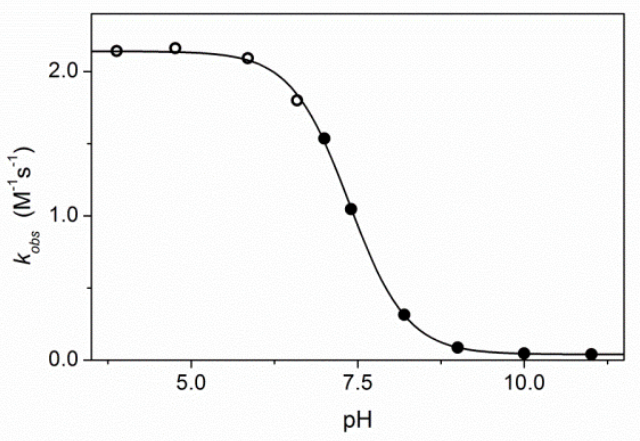

Fig. 2 The $\mathrm{pH}$ dependence of the pseudo-second order rate constant for the oxidation of pyruvate ion by $\mathrm{Cl}(\mathrm{I})$. Experimental rate constants were obtained by the quenched stopped-flow method (open circles) and conventional kinetic experiments (filled circles). The result of fitting to equation 7 is also shown (solid line). $I=1.0 \mathrm{M}\left(\mathrm{NaClO}_{4}\right), T=25.0^{\circ} \mathrm{C}$.

$$
\mathrm{OCl}^{-}+\mathrm{H}^{+}=\mathrm{HOCl} K_{\mathrm{p}}^{\mathrm{OCl}}=\frac{[\mathrm{HOCl}]}{\left[\mathrm{H}^{+}\right]\left[\mathrm{OCl}^{-}\right]}
$$

The pseudo-second-order rate constant is expressed as follows:

$$
k_{\mathrm{obs}}=k_{\mathrm{HOCl}} \frac{K_{\mathrm{p}}^{\mathrm{OCl}}\left[\mathrm{H}^{+}\right]}{1+K_{\mathrm{p}}^{\mathrm{OCl}}\left[\mathrm{H}^{+}\right]}+k_{\mathrm{OCl}} \frac{1}{1+K_{\mathrm{p}}^{\mathrm{OCl}}\left[\mathrm{H}^{+}\right]}
$$

where $k_{\mathrm{HOCl}}, k_{\mathrm{OCl}}$ and $K_{\mathrm{p}}^{\mathrm{OCl}}$ are the rate constants of the oxidation by $\mathrm{HOCl}, \mathrm{OCl}^{-}$and the protonation constant of $\mathrm{OCl}^{-}$, respectively. In agreement with observations in related systems, the acidic form of hypochlorous acid oxidizes the substrate more readily than the basic form. The experimental data were fitted to equation (7) and the results are listed in Table 1. The fitted value for $K_{\mathrm{p}}{ }^{\mathrm{OCl}}$ from the kinetic experiments agrees well with the data reported in earlier literature ${ }^{47}$ and obtained from $\mathrm{pH}$-metric titrations in the present study.

The oxidation by $\mathrm{HOCl}$ is the main path of the reaction. The activation parameters for this path were determined by studying the temperature dependence of $k_{\text {obs }}$ at $\mathrm{pH} 2.8$ in the 10 $45{ }^{0} \mathrm{C}$ temperature range. Under such conditions, pyruvic acid is fully deprotonated and the contribution of the $\mathrm{OCl}^{-}$path is negligible, i.e. $k_{\mathrm{obs}} \approx k_{\mathrm{HOCl}}$. The activation parameters, $\Delta S^{\ddagger}$ and $\Delta H^{\ddagger}$, were calculated by fitting the $k_{\text {obs }}$ values to the Eyringequation (eq. 8) using a non-linear least squares fitting algorithm (Fig. S2, ESI $\dagger$ ). The results are listed in Table 1.

$$
k_{\mathrm{HOCl}}=\frac{k^{\prime} T}{h} e^{\frac{\Delta S_{\mathrm{HOCl}}^{ \pm}}{R}} e^{\frac{-\Delta H_{\mathrm{HOCl}}^{\ddagger}}{R T}}
$$

\section{Kinetic studies under acidic conditions}

Typical stopped-flow traces under $\mathrm{pH} 2.5$ show two distinct steps, which complete within a few seconds and several minutes, respectively. When one of the reactants is used in large excess, each step of the kinetic traces can be fitted to a simple exponential expression yielding two pseudo first order rate constants. This observation is somewhat unexpected because no immediate reason can be seen why the simple kinetic pattern of the redox reaction changes at low $\mathrm{pH}$. A 
sudden drop of the $\mathrm{pH}$ occurred upon mixing the reactants in these experiments and it was concluded that an additional acid induced chemical reaction may contribute to the overall process. For example, the formation of chlorine from hypochlorous acid is enhanced by increasing the acid concentration, but this reaction requires relatively large chloride ion concentration. Chloride ion free reagents were used and only small amounts of this species formed in this study when the oxidation proceeded, therefore, any interference from chlorine formation could be excluded.

Table 1 Equilibrium constants and kinetic parameters for the pyruvic acid - chlorine(I) reaction

\begin{tabular}{lcll}
\hline Parameter & Value & Unit & Remark \\
\hline $\lg K_{\mathrm{p}} \mathrm{OCl}$ & 7.40 & & Ref. 47 \\
& $7.37 \pm 0.01$ & & a \\
$\mathrm{k}_{\mathrm{OCl}}$ & $(3.97 \pm 0.05) 10^{-2}$ & $\mathrm{M}^{-1} \mathrm{~s}^{-1}$ & a \\
$\mathrm{k}_{\mathrm{HOCl}}$ & $2.14 \pm 0.02$ & $\mathrm{M}^{-1} \mathrm{~s}^{-1}$ & a, slightly acidic - alkaline region \\
$\mathrm{k}_{\mathrm{HOCl}} \neq$ & $2.20 \pm 0.04$ & $\mathrm{M}^{-1} \mathrm{~s}^{-1}$ & a, acidic region \\
$\Delta H_{\mathrm{HOCl}}$ & $(9.1 \pm 2.0) 10^{-2}$ & $\mathrm{M}^{-1} \mathrm{~s}^{-1}$ & a, acidic region \\
$\Delta S_{\text {HOCl }}$ & $34.6 \pm 1.2$ & $\mathrm{kJmol}^{-1}$ & a \\
$K_{\mathrm{p}}$ & $-120.3 \pm 3.6$ & $\mathrm{Jmol}^{-1} \mathrm{~K}^{-1}$ & $\mathrm{a}$ \\
\hline
\end{tabular}

a: this work

According to literature data, $\log K_{\mathrm{p}}=1.97$ for pyruvate ion $^{63}$, thus, it is reasonable to assume that one of the reaction steps is somehow associated with the protonation of this species. In order to explore this possibility, kinetic traces were recorded by acidifying neutral solutions of pyruvate ion in the absence of hypochlorous acid. First order absorbance changes were observed and the pseudo-first-order rate constants agreed well with that of the faster reaction step in the oxidation experiments at the same $\mathrm{pH}$ and pyruvate ion concentration. However, simple proton transfer reactions are diffusion controlled and the protonation of pyruvate ion to pyruvic acid is expected to complete far within the dead-time of the stoppedflow experiments under the conditions applied. It follows that these observations cannot be interpreted by considering only the protonation step, instead, it needs to be assumed that the absorbance change is associated with a slower process triggered by the protonation of pyruvic acid.

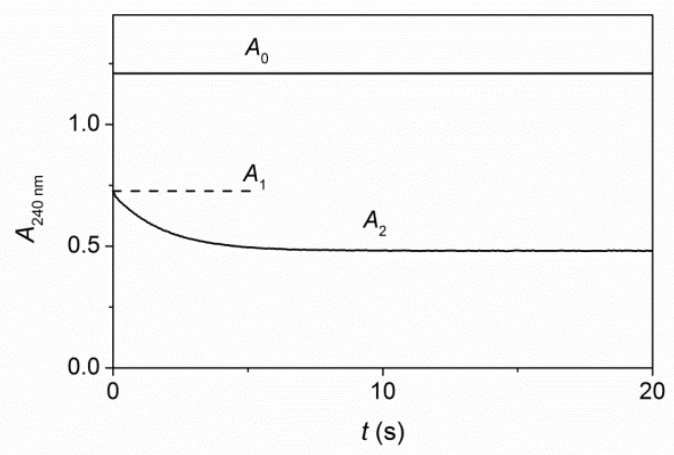

Fig.3 Typical absorbance change upon mixing the solution of pyruvate ion with perchloric acid $\left(A_{2}\right)$. For comparison, the absorbance obtained by dilution of the same pyruvate ion solution with neutral background electrolyte solution is also shown $\left(A_{0}\right)$. Upon acidifying the pyruvate ion solution, the absorbance drops to $A_{1}$ within the dead-time of the instrument. $\quad C_{\mathrm{PYR}}{ }^{0}=5.00 \times 10^{-3} \mathrm{M}, \mathrm{pH}=1.50, I=1.0 \mathrm{M}$ $\left(\mathrm{NaClO}_{4}\right), T=25.0^{\circ} \mathrm{C}$.

A thorough inspection of the kinetic traces confirms this assumption. As shown in Fig. 3, there is a sudden absorbance drop from $A_{0}$ to $A_{1}$ within the dead-time of the instrument followed by a slower process associated with an additional absorbance change saturating at $A_{2}$.

It is well documented that $\alpha$-ketocarboxylic acids are involved in keto-enol and hydration equilibria. ${ }^{63-66}$ Scheme 1 shows all the possible equilibrium steps together with the corresponding equilibrium constants for the pyruvate system. ${ }^{63}$
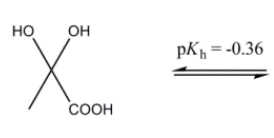

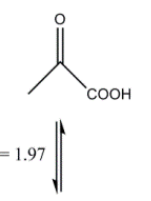
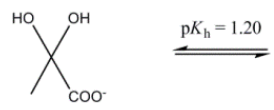<smiles>COC(C)=O</smiles>

$+\mathrm{H}^{+}$

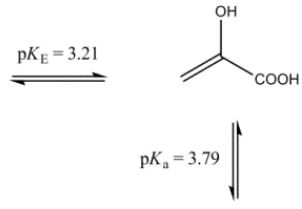

$\stackrel{\mathrm{p} K_{\mathrm{E}}=5.03}{\rightleftharpoons}$<smiles>C=C(O)O</smiles>

$+\mathrm{H}^{+}$

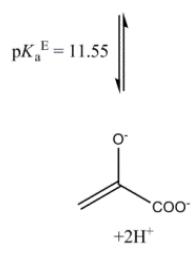

Scheme 1 Acid - base, keto - enol and hydration equilibria in aqueous solution of pyruvate ion. Reproduced from Ref. [63].

According to the data in Scheme 1, the enolic form of pyruvic acid and pyruvate ion is present in less than 0.1 and $0.01 \%$, respectively and the hydrated form of pyruvate ion is also negligible. In contrast, the hydration of pyruvic acid is substantial, and the keto and hydrated forms are present in comparable concentrations under acidic conditions. ${ }^{1} \mathrm{H}$ NMR studies support this overall model and the $\mathrm{pH}$ dependence of the $\mathrm{CH}_{3}$ peak of pyruvic acid is consistent with the simultaneous presence of the keto and hydrated forms (Fig. S3, ESI $\dagger$ ). These features offer a possibility for coherent interpretation of the experimental observations by the following reaction steps. 


$$
\operatorname{pyr}^{-}+\mathrm{H}^{+}=\operatorname{Hpyr} K_{\mathrm{p}}^{\mathrm{PYR}}=\frac{[\mathrm{Hpyr}]}{\left[\mathrm{H}^{+}\right]\left[\mathrm{pyr}^{-}\right]}
$$

$$
\mathrm{Hpyr}+\mathrm{H}_{2} \mathrm{O}=\operatorname{Hpyr}\left(\mathrm{H}_{2} \mathrm{O}\right) \quad K_{\mathrm{h}}=\frac{\left[\operatorname{Hpyr}\left(\mathrm{H}_{2} \mathrm{O}\right)\right]}{[\mathrm{Hpyr}]} k_{\mathrm{h},} k_{-\mathrm{h}}
$$

where $K_{\mathrm{p}}{ }^{\mathrm{PYR}}, K_{\mathrm{h}}, k_{\mathrm{h}}$, and $k_{-\mathrm{h}}$ are the protonation constant, hydration equilibrium constant, forward and backward hydration rate constants, respectively. Thus, the sudden drop of the absorbance is due to the fast protonation of pyruvate ion. This is a pre-equlibrium followed by the hydration of the ketoform of pyruvic acid. The hydration stabilizes the acidic form of pyruvate and an apparent protonation constant, $K_{\mathrm{p}}$, , can also be defined as follows:

$$
K_{\mathrm{p}}^{\prime}=\frac{[\mathrm{Hpyr}]+\left[\operatorname{Hpyr}\left(\mathrm{H}_{2} \mathrm{O}\right)\right]}{\left[\mathrm{H}^{+}\right]\left[\mathrm{pyr}^{-}\right]}=K_{\mathrm{p}}^{\mathrm{PYR}}\left(1+K_{\mathrm{h}}\right)
$$

The plots of $A_{1}$ and $A_{2}$ as a function of $\mathrm{pH}$ are consistent with such protolytic steps and allow the calculation of $K_{\mathrm{p}}$ and $K_{\mathrm{h}}$ by fitting $A_{1}$ and $A_{2}$ simultaneously to the following expressions:

$$
A_{1}=\frac{\varepsilon_{\mathrm{pyr}}+\varepsilon_{\mathrm{Hpyr}} K_{\mathrm{p}}^{\mathrm{PYR}}\left[\mathrm{H}^{+}\right]}{1+K_{\mathrm{p}}^{\mathrm{PYR}}\left[\mathrm{H}^{+}\right]}
$$

$$
A_{2}=\frac{\varepsilon_{\mathrm{pyr}}+\varepsilon_{\mathrm{Hpyr}} K_{\mathrm{p}}^{\mathrm{PYR}}\left[\mathrm{H}^{+}\right]+\varepsilon_{\mathrm{Hpyrh}} K_{\mathrm{p}}^{\mathrm{PYR}} K_{\mathrm{h}}\left[\mathrm{H}^{+}\right]}{1+K_{\mathrm{p}}^{\mathrm{PYR}}\left[\mathrm{H}^{+}\right]\left(1+K_{\mathrm{h}}\right)}
$$

where $\varepsilon_{\mathrm{pyr}}, \varepsilon_{\mathrm{Hpyr}}$ and $\varepsilon_{\mathrm{Hpyrh}}$ are the molar absorbance of $\mathrm{pyr}^{-}$, Hpyr and $\mathrm{Hpyr}\left(\mathrm{H}_{2} \mathrm{O}\right)$, respectively. The experimental data were fitted simultaneously to equations 12 and 13 (Fig. 4) and the estimated parameters are listed in Table 2.

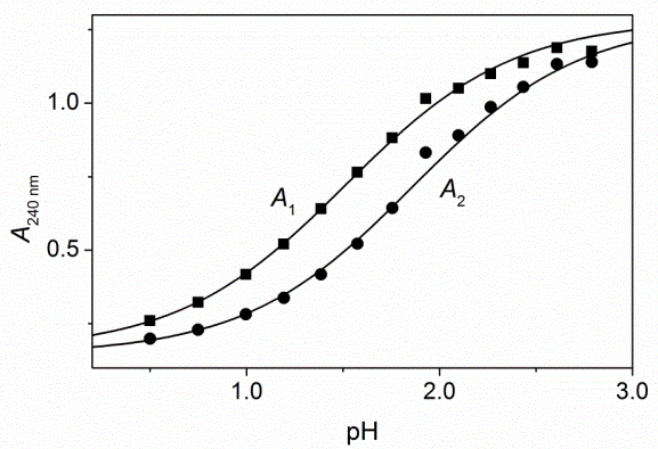

Fig. 4 The characteristic absorbance values upon mixing the solution of pyruvate ion with perchloric acid, cf. Figure 3 . The experimental data (dots and squares) were fitted simultaneously to equations 12 and 13 (solid lines) $C_{\mathrm{PYR}}{ }^{0}=$ $5.00 \times 10^{-3} \mathrm{M}, I=1.0 \mathrm{M}\left(\mathrm{NaClO}_{4}\right), T=25.0^{\circ} \mathrm{C}$.

Table 2Equilibrium constants and kinetic parameters for the protolytic equilibria and hydration of pyruvic acid

\begin{tabular}{lcll}
\hline Parameter & Value & Unit & Remark \\
\hline $\mathrm{K}_{\mathrm{p}}{ }^{\text {PYR }}$ & 93.3 & $\mathrm{M}^{-1}$ & Ref. [63] \\
$\mathrm{K}_{\mathrm{h}}$ & $32.5 \pm 2.0$ & $\mathrm{M}^{-1}$ & $\mathrm{a}$ \\
$\mathrm{K}_{\mathrm{p}}$ & $1.2 \pm 0.1$ & & $\mathrm{a}$ \\
& 72.2 & $\mathrm{M}^{-1}$ & a, calculated value, eq. 11 \\
$\mathrm{k}_{\mathrm{h} 0}$ & $57.2 \pm 3.4$ & $\mathrm{M}^{-1}$ & a, fitted value, eq. 16 \\
$\mathrm{k}_{\mathrm{h} 1}$ & $0.24 \pm 0.01$ & $\mathrm{~s}^{-1}$ & $\mathrm{a}$ \\
$\varepsilon_{\mathrm{pyr}}$ & $5.5 \pm 0.2$ & $\mathrm{M}^{-1} \mathrm{~s}^{-1}$ & $\mathrm{a}$ \\
$\varepsilon_{\mathrm{Hpyr}}$ & $256.6 \pm 3.4$ & $\mathrm{M}^{-1} \mathrm{~cm}^{-1}$ & $\mathrm{a}$ \\
$\varepsilon_{\text {Hpyrh }}$ & $31.8 \pm 2.1$ & $\mathrm{M}^{-1} \mathrm{~cm}^{-1}$ & $\mathrm{a}$ \\
\hline
\end{tabular}

a: this work

The calculated protonation constant of pyruvate ion is about three times smaller than the value reported earlier. ${ }^{63}$ This is partly due to the difference in the experimental conditions applied, however, other factors should also be considered. The protonation constant was estimated by introducing various approximations in the evaluation of the experimental data in the earlier study. This could easily lead to biased results. In our case, the equilibrium constants were calculated directly from stopped-flow photometric experimental data which are expected to provide more reliable results.

The pseudo-first-order rate constant of hydration increases with increasing $\left[\mathrm{H}^{+}\right]$indicating that the reaction of pyruvic acid is acid catalyzed (Fig. 5). The corresponding rate constants can be expressed as follows:

$$
k_{\mathrm{h}}=k_{\mathrm{h} 0}+k_{\mathrm{h} 1}\left[\mathrm{H}^{+}\right] \quad k_{-\mathrm{h}}=k_{-\mathrm{h} 0}+k_{-\mathrm{h} 1}\left[\mathrm{H}^{+}\right]
$$

where $k_{\mathrm{h} 0}, k_{-\mathrm{h} 0}$ and $k_{\mathrm{h} 1,} k_{-\mathrm{h} 1}$ are the forward and reverse rate constants for the non-catalytic and acid catalysed paths of hydration, respectively.

The protonation equilibrium of pyruvate ion is expected to be diffusion controlled and the $\mathrm{pH}$ dependence of the pseudo first order rate constant of hydration, $k_{\mathrm{obs}} \mathrm{h}$, is given by the following expression: 
$k_{\mathrm{obs}}^{\mathrm{h}}=\frac{k_{\mathrm{h} 1}\left(1+\frac{1}{K_{\mathrm{p}}^{\mathrm{PYR}}}\right) K_{\mathrm{p}}^{\mathrm{PYR}}\left[\mathrm{H}^{+}\right]^{2}+\frac{k_{\mathrm{h} 1}\left[\mathrm{H}^{+}\right]}{K_{\mathrm{h}}}+k_{\mathrm{h} 0}\left(1+\frac{1}{1+K_{\mathrm{h}}}\right) K_{\mathrm{p}}^{\mathrm{PYR}}\left[\mathrm{H}^{+}\right]+\frac{k_{\mathrm{h} 0}}{K_{\mathrm{h}}}}{1+K_{\mathrm{p}}^{\mathrm{PYR}}\left[\mathrm{H}^{+}\right]}$

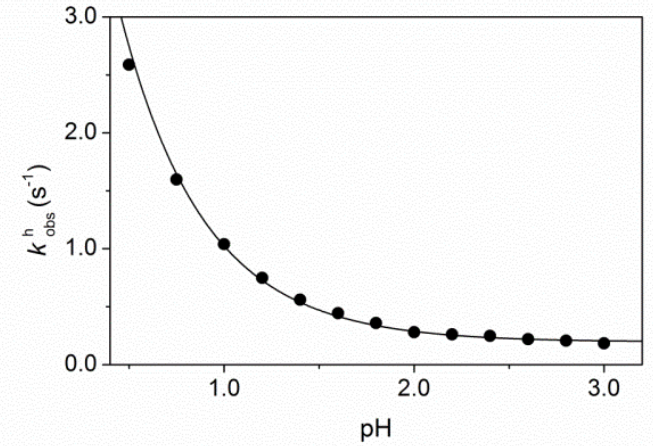

Fig. 5 The $\mathrm{pH}$ dependence of the pseudo-first-order rate constant for the hydration of pyruvic acid: experimental data (circles) and the fitted results on the basis of equation 15 (solid line). $\lambda=240 \mathrm{~nm}, C_{\mathrm{PYR}}{ }^{0}=5.00 \times 10^{-3} \mathrm{M}, I=1.0 \mathrm{M}\left(\mathrm{NaClO}_{4}\right), T=$ $25.0^{\circ} \mathrm{C}$.

The forward and reverse rate constants of hydration were calculated by fitting $k_{\mathrm{obs}}{ }^{\mathrm{h}}$ to equation (15) using fixed values for $K_{\mathrm{p}}$ and $K_{\mathrm{h}}$. The results are listed in Table 2. In an earlier study, the rate of dehydration of hydrated pyruvic acid was found to be dependent on the pyruvate ion concentration. ${ }^{64}$ This is in sharp contrast with our finding because the rate constant is independent of pyruvate ion concentration in the $5.0 \times 10^{-4}-$ $1.0 \times 10^{-2} \mathrm{M}$ concentration range. Furthermore, according to our results the proton catalyzed step is considerably slower and the non-catalytic reaction is much faster than it was reported earlier. It is difficult to identify the main reasons for such differences but several factors should be considered. The technical setup of the kinetic experiments was less sophisticated in the cited study and it is not clear how the relatively fast reactions could be monitored with any acceptable reliability. In addition, the kinetic runs were made with pre-acidified pyruvic acid solutions which may undergo slow decomposition. If the reagent solutions were prepared long before the kinetic experiments, the products of the acidic decomposition could easily interfere with the kinetic studies. Such problems were circumvented in this study by using neutral pyruvate ion solutions as a reactant.

The $\mathrm{pH}$ dependence of the rate of the hydration of pyruvic acid can be interpreted by considering the structural features of $\alpha$-keto carboxylic acids. The acid catalysis confirms that pyruvic acid is involved in the formation of a protonated species along the hydration process. The protonation most likely occurs at the carbonyl group of pyruvic acid, and the formation of an internal hydrogen bond to the carboxylic group may stabilize this intermediate. Such a structure may enhance the possibility of a nucleophile attack by a water molecule at the partially positive carbon atom of the carbonyl group (Scheme 2).

Under acidic conditions, the fast step in the pyruvate ion $\mathrm{HOCl}$ reaction is consistent with the results obtained for the hydration of pyruvic acid. It follows that the slower step in Figure 6 corresponds to the oxidation of pyruvate ion. The hydration and protonation reactions should be considered as fast pre-equilibria with respect to the redox process. The pseudo first order rate constant is linearly dependent on the concentration of both pyruvate ion and $\mathrm{HOCl}$ concentration when they are used in large excess over the other reactant (Fig. $\mathrm{S} 4, \mathrm{ESI} \dagger)$. Thus, the redox reaction remains first order for each reactant under acidic condition. The $\mathrm{pH}$ dependence of $k_{\mathrm{obs}}$ clearly demonstrates that the reaction between the deprotonated form of the substrate and $\mathrm{HOCl}$ is the main reaction path in the redox process and the reaction with $\mathrm{Hpyr}$ has minor contribution (Fig. 7).<smiles>CC1(O)OC=CO1</smiles>

Scheme 2. The proposed structure of the possible intermediate in the proton catalyzed hydration of pyruvic acid.

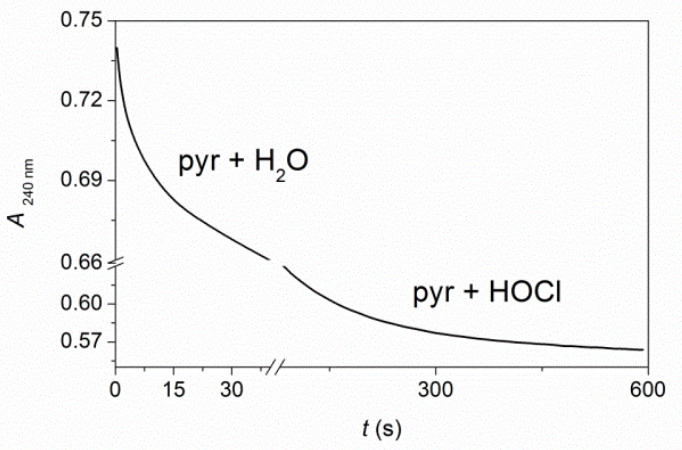

Fig. 6 Typical kinetic trace for the oxidation of pyruvic acid by hypochlorous acid under acidic conditions. $C_{\mathrm{PYR}}{ }^{0}=1.00 \times 10^{-2}$ $\mathrm{M}, C_{\mathrm{HOCl}}{ }^{0}=1.00 \times 10^{-3} \mathrm{M}, \mathrm{pH}=1.50, I=1.0 \mathrm{M}\left(\mathrm{NaClO}_{4}\right), T=25.0$ ${ }^{\circ} \mathrm{C}$.

Since the hydration of pyruvic acid is much faster than the redox reaction, the $\mathrm{pH}$ profile shown in Figure 7 can be interpreted by considering the formal protonation constant of pyruvic acid, $K_{\mathrm{p}}$ '. The pseudo-first order rate constant, $k_{\mathrm{obs}}$, was fitted to the following expression:

$$
k_{\mathrm{obs}}=\frac{1}{1+K_{\mathrm{p}}^{\prime}\left[\mathrm{H}^{+}\right]} k_{\mathrm{HOCl}}+\frac{K_{\mathrm{p}}^{\prime}\left[\mathrm{H}^{+}\right]}{1+K_{\mathrm{p}}^{\prime}\left[\mathrm{H}^{+}\right]} k_{\mathrm{HOCl}}^{\prime}
$$

where $k_{\mathrm{HOCl}}$ is the rate constant for the reaction of $\mathrm{Hpyr}$ withHOCl. The fitted values for $k_{\mathrm{HOCl}}, k_{\mathrm{HOCl}}$ ' and $K_{\mathrm{p}}$ ' are listed in Table 1. These data are in reasonable agreement with the results obtained from other experiments. (Tables 1 and 2) 


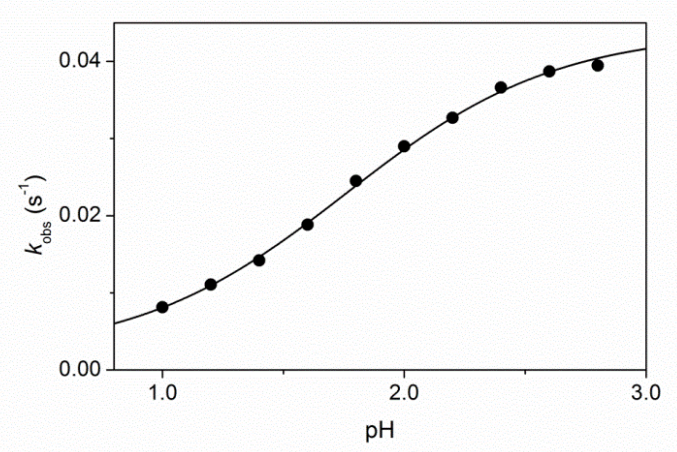

Fig. 7 The $\mathrm{pH}$ dependence of the pseudo-first-order rate constant for the oxidation of pyruvic acid by hypochlorous acid under acidic conditions: experimental data (circles) and the fitted results on the basis of equation 18 (solid line).). $\lambda=325$ $\mathrm{nm}, C_{\mathrm{PYR}}{ }^{0}=2.00 \times 10^{-2} \mathrm{M}, C_{\mathrm{HOCl}}{ }^{0}=1.00 \times 10^{-3} \mathrm{M}, I=1.0 \mathrm{M}$ $\left(\mathrm{NaClO}_{4}\right), T=25.0^{\circ} \mathrm{C}$.

\section{Mechanistic considerations and DFT calculations}

The simplest way to envision the oxidation of pyruvate ion by hypochlorous acid is to assume an O-atom transfer step between the reactants. Because of the simplicity of the reaction, there are limited options to confirm experimentally the validity of this assumption. With obvious limitations and cautiousness, the activation parameters can be used to test the mechanism. The comparison of activation entropies for related reactions is particularly informative, but the significance of the conclusions obtained in this way should never be overrated. In a recent study, activation parameters were reported for the oxidation of amaranth by hypochlorous acid. ${ }^{67}$ These literature data could be an obvious choice for comparative evaluation of our results. However, an inspection of that paper reveals that fast preequilibrium between hypochlorous acid and its basic form was ignored during the evaluation of the kinetic data. This led to false interpretation of the kinetic results and the corresponding activation parameters need to be termed as erroneous.

Recently, we have demonstrated that O-transfer steps are associated with relatively large negative entropies of activation in simple oxidation reactions of oxone. ${ }^{68}$ This is most likely the consequence of significant geometrical rearrangements associated with the reaction. An O-transfer step would also require massive geometrical changes in the pyruvate ion hypochlorous acid reaction and, therefore, be consistent with a large negative entropy of activation which, in fact, was observed in this system (Table 1). This indicates that a simple O-transfer is probably also operative in the pyruvate ion hypochlorous acid reaction. The formation of acetic acid requires that the incoming oxygen attacks the carbonyl group and the actual reaction path may include some sort of an intramolecular interaction between the reactants, which is followed by concerted rearrangement of the chemical bonds.

The DFT calculations lend support to this assumption. Energy profiles were calculated for the reaction between pyruvate ion and $\mathrm{HOCl}$. Alternatively, one water molecule was also added to the model checking the possible role of the solvent molecule. The optimized transition states are shown in Figure 8. Substantial differences between the structural arrangements of the reactants in the transition state were not found in the absence and presence of a water molecule. The calculations predict that the reaction is thermodynamically highly favored (Table S2, ESI $\uparrow$ ). The oxidation is a concerted process where the bond-lengths of the reactants are changing simultaneously. Thus, the $\mathrm{HO}-\mathrm{Cl}$ and the $\mathrm{C}_{\text {carboxyl }}-\mathrm{C}_{\text {carbonyl }}$ bonds are elongated somewhat while the $\mathrm{C}_{\text {carbonyl }}-\mathrm{OH}$ bond is shortened along the reaction coordinate and the water molecule assists this process via hydrogen bonds.
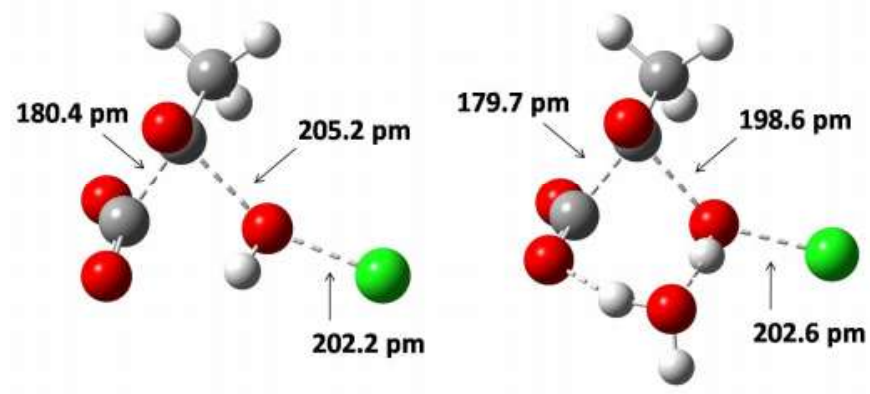

Fig. 8 The transition states in the pyruvate ion $-\mathrm{HOCl}$ reaction in the absence and presence of one water molecule calculated at the $M 06 / 6-311+G(d, p)$ level.

As expected, the oxidation involves the attack of the Oatom of $\mathrm{HOCl}$ on the carbon atom of the carbonyl group. The results can easily be conceptualized by considering that the carbon atom is partially positive and as such it is prone to a nucleophile attack by the partially negative moiety of the oxidant. The structure of the transition state suggests a very plausible interpretation of the mechanism of the reaction. The rearrangement of the activated complex can easily lead to simultaneous formation of a $\mathrm{C}-\mathrm{O}$ bond at the carbonyl site, the breakage of the $\mathrm{C}-\mathrm{C}$ bond, the release of the chloride ion and a proton transfer from $\mathrm{HOCl}$ to the water molecule. This concerted rearrangement of the primary and secondary chemical bonds explains the relatively large entropy of activation observed experimentally. Calculations at various theoretical levels do not predict significant differences in the activation Gibbs free energies $\left(\Delta G^{\neq}\right)$(Table 3$)$. The added water molecule decreases the $\Delta \mathrm{G}^{\neq}$values and makes more exergonic the process. This effect is more pronounced when we use M06 functional and larger basis sets. The structures of the transition states and the related imaginary frequencies are given in the ESI† (Table S3).

\section{Conclusions}

The results presented here confirm that the oxidation of pyruvic acid by hypochlorous acid is a strongly $\mathrm{pH}$ dependent process. The main oxidation path involves $\mathrm{HOCl}$ and the deprotonated form of pyruvic acid. The kinetic observations can be interpreted by a simple rate equation which is first order in both reactants. Under acidic conditions, the kinetic traces feature two distinct first order steps. The faster process is associated with the hydration of the substrate and can be treated as a fast preequilibrium compared to the oxidation process. The entropy of activation for the oxidation is consistent with an O-transfer process, and the results of DTF calculations confirm this conclusion. 
Table 3The calculated activation Gibbs free energies of the pyruvate ion $-\mathrm{HOCl}$ and the pyruvate ion $-\mathrm{HOCl}-\mathrm{H}_{2} \mathrm{O}$ systems $($ in $\mathrm{kJmol}^{-1}$ )

\begin{tabular}{llcc}
\hline Functional & Basis sets & pyruvate ion $-\mathrm{HOCl}$ & pyruvate ion $-\mathrm{HOCl}-\mathrm{H} 2 \mathrm{O}$ \\
\hline B3LYP & $6-31+\mathrm{G}(\mathrm{d}, \mathrm{p})$ & 133.7 & 129.2 \\
& $6-311+\mathrm{G}(\mathrm{d}, \mathrm{p})$ & 124.6 & 121.9 \\
M06 & $6-31+\mathrm{G}(\mathrm{d}, \mathrm{p})$ & 127.3 & 113.7 \\
& $6-311+\mathrm{G}(\mathrm{d}, \mathrm{p})$ & 119.8 & 101.9 \\
\hline
\end{tabular}

\section{Acknowledgements}

The authors thank the Hungarian Science Foundation forfinancial support under grant no NK 105156. Theresearch was supported by the EU and co-financed by the EuropeanSocial Fund under the projects ENVIKUT (TAMOP4.2.2.A-11/1/KONV-2012-0043) and Supercomputer, the national virtual lab (grant no.: TAMOP-4.2.2.C-11/1/KONV2012-0010). Dr. Zsolt Baranyai and Mr. Tibor Deczkiare gratefully acknowledged for their assistance in some of the experiments.

\section{Notes}

${ }^{a}$ MTA-DE Homogeneous Catalysis and Reaction Mechanisms Research Group, Debrecen, Hungary, H-4032

${ }^{b}$ Department of Inorganic and Analytical Chemistry, University of Debrecen, Debrecen, Hungary, H-4032. email:

ifabian@science.unideb.hu

$\dagger$ Electronic Supplementary Information (ESI) available: Figures showing the spectra of the reactants, the temperature dependence of $k_{\mathrm{obs}}$ at $\mathrm{pH} 2.8$, the ${ }^{1} \mathrm{H}$ NMR spectra of pyruvic acid as a function of $\mathrm{pH}, k_{\mathrm{obs}}$ as the function of $\mathrm{HOCl}$ concentration at $\mathrm{pH} 1.0$; tables on the stoichiometry of the reaction, and DFT results on the Gibbs free energies and coordinates of the transition state.. See DOI: 10.1039/b000000x/

\section{References}

1. R. Aranda-Rodriguez, B. Koudjonou, B. Jay, G. L. Lebel and F. M. Benoit, Water Qual. Res. J. Canada, 2008, 43, 11-22.

2. B. R. Deshwal, D. S. Jin, S. H. Lee, S. H. Moon, J. H. Jung and H. K. Lee, J. Haz. Mat., 2008, 150, 649-655.

3. D. Feretti, I. Zerbini, E. Ceretti, M. Villarini, C. Zani, M. Moretti, C. Fatigoni, G. Orizio, F. Donato and S. Monarca, Water Res., 2008, 42, 4075-4082.

4. D. J. Stewart, M. J. Napolitano, E. V. Bakhmutova-Albert and D. W. Margerum, Inorg. Chem., 2008, 47, 1639-1647.

5. L. A. Keskinen, A. Burke and B. A. Annous, Int. J. Food Microbiol., 2009, 132, 134-140.

6. M. Mahovic, J. A. Bartz, K. R. Schneider and J. D. Tenney, J. Food Prot., 2009, 72, 952-958.

7. M. J. McGuire, X. Y. Wu, N. K. Blute, D. Askenaizer and G. Qin, J. Am. Water Works. Ass., 2009, 101, 47-59.

8. V. Tarvo, T. Lehtimaa, S. Kuitunen, V. Alopaeus and T. Vuorinen, J. Wood Chem. Technol., 2009, 29, 191-213.
9. M. J. Zdilla, A. Q. Lee and M. M. Abu-Omar, Inorg. Chem., 2009, 48, 2260-2268.

10. T. Lehtimaa, S. Kuitunen, V. Tarvo and T. Vuorinen, Holzforschung, 2010, 64, 555-561.

11. S. D. Hicks, J. L. Petersen, C. J. Bougher and M. M. Abu-Omar, Angew. Chem.-Int. Edit., 2011, 50, 699-702.

12. P. Ufermann, H. Petersen and M. Exner, Int. J. Hyg. Environ. Health., 2011, 215, 86-90.

13. T. P. Umile and J. T. Groves, Angew. Chem.-Int. Edit., 2011, 50, 695698.

14. T. P. Umile, D. Wang and J. T. Groves, Inorg. Chem., 2011, 50, 10353-10362.

15. B. Blanc, J. A. Mayfield, C. A. McDonald, G. S. Lukat-Rodgers, K. R. Rodgers and J. L. DuBois, Biochemistry, 2012, 51, 1895-1910.

16. Pyruvic acid and hypochlorous acid are involved in fast protolytic equilibria with the corresponding basic forms. The terms pyruvate ion and hypochlorous acid are used in a general context thorough the paper, the acidic and basic forms of these species are distinguished only if it is necessary for the clarity of the discussion.

17. E. A. Mazzio, R. R. Reams and K. F. A. Soliman, Brain Res., 2004, 1004, 29-44.

18. K. R. Hegde, S. Kovtun and S. D. Varma, J. Ocular Pharmacol. Ther., 2007, 23, 492-502.

19. T. Green, A. Grigorian, A. Klyuyeva, A. Tuganova, M. Luo and K. M. Popov, J. Biol. Chem., 2008, 283, 15789-15798.

20. R. A. Olek, W. Ziolkowski, J. J. Kaczor, T. H. Wierzba and J. Antosiewicz, Biosci. Biotechnol. Biochem., 2011, 75, 500-504.

21. R. Andreozzi, V. Caprio, A. Insola, R. Marotta and V. Tufano, Water Res., 1998, 32, 1492-1496.

22. R. Andreozzi, V. Caprio, R. Marotta and V. Tufano, Water Res., 2001, 35, 109-120.

23. A. Das and S. Mukhopadhyay, Transit. Met. Chem., 2004, 29, 797803.

24. B. B. Dhar, R. Mukherjee, S. Mukhopadhyay and R. Banerjee, Eur. J. Inorg. Chem., 2004, 4854-4858.

25. P. C. Mandal, S. Das and S. Mukhopadhyay, Int. J. Chem. Kin., 2010, 42, 323-335.

26. W. W. Li, Z. M. Qiang, T. Zhang and F. L. Cao, Appl.Catal. BEnviron., 2012, 113, 290-295.

27. G. C. White, Handbook of Chlorination and Alternative Disinfectants, Van Nostrand Reinhold, New York, 1992.

28. M. Deborde and U. von Gunten, Water Res., 2008, 42, 13-51.

29. K.-H. Chen, Y.-J. Shih and Y.-H. Huang, J. Env. Manag., 2013, 121, $1-5$. 
30. R. Zhao, Y. Tang, S. Wei, X. Xu, X. Shi and G. Zhang, Reaction Kinetics Mechanisms and Catalysis, 2012, 106, 37-47.

31. C. Liu, U. von Gunten and J.-P. Croue, Environ. Sci. Technol., 2012, 46, 11054-11061.

32. H. M. Abu-Soud, D. Maitra, J. Byun, C. E. A. Souza, J. Banerjee, G. M. Saed, M. P. Diamond, P. R. Andreana and S. Pennathur, Free Rad. Biol. Med., 2012, 52, 616-625.

33. J. L. Beal, S. B. Foster and M. T. Ashby, Biochemistry, 2009, 48, 11142-11148.

34. J. Kim, H. J. Park, J. H. Lee, J. S. Hahn, M. B. Gu and J. Yoon, Water Res., 2009, 43, 5252-5259.

35. G. C. Higgins, P. M. Beart, Y. S. Shin, M. J. Chen, N. S. Cheung and P. Nagley, J. Alzheimers Dis., 2010, 20, S453-S473.

36. Q. Xu, K.-A. Lee, S. Lee, K. M. Lee, W.-J. Lee and J. Yoon, J. Am. Chem. Soc., 2013, 135, 9944-9949.

37. S. Sibanda, B. J. Parsons, C. Houee-Levin, J. L. Marignier, A. W. J. Paterson and D. J. Heyes, Free Rad. Biol. Med., 2013, 63, 126-134.

38. Z. Run, Y. Zhiqiang, S. Bo, D. Zhichao, A. Xin and Y. Jingli, Inorg. Chem., 2013, 52, 10325-10331.

39. B. J. Parsons, S. Sibanda, D. J. Heyes and A. W. J. Paterson, Free Rad. Biol. Med., 2013, 61, 111-118.

40. A. S. Campbell, C. Dong, J. S. Dordick and C. Z. Dinu, Process Biochemistry, 2013, 48, 1355-1360.

41. P. Nagy and M. T. Ashby, Chem. Res. Toxicol., 2005, 18, 919-923.

42. P. Nagy and M. T. Ashby, J. Am. Chem. Soc., 2007, 129, 1408214091.

43. P. Nagy and M. T. Ashby, Chem. Res. Toxicol., 2007, 20, 79-87.

44. B. A. Xulu and M. T. Ashby, Biochemistry, 2010, 49, 2068-2074.

45. M. M. Stacey, S. L. Cuddihy, M. B. Hampton and C. C. Winterbourn, Archives of Biochemistry and Biophysics, 2012, 527, 45-54.

46. G. Peintler, I. Nagypal and I. R. Epstein, J. Phys. Chem., 1990, 94, 2954-2958.

47. L. C. Adam, I. Fabian, K. Suzuki and G. Gordon, Inorg. Chem., 1992, 31, 3534-3541.

48. A. I. Vogel, Quantitative Inorganic Analysis, 3rd ed., Longman, London, 1961.

49. I. Fábián and G. Gordon, Inorg. Chem., 1991, 30, 3785-3787.

50. I. Fábián and G. Lente, Pure Appl. Chem., 2010, 82, 1957-1973.

51. SCIENTIST v. 2.01, (1995) Micromath Software, Salt Lake City, UT.

52. ORIGIN v. 9.1, (2014) Microcal Software Inc., Northampton, MA.

53. A. D. Becke, J. Chem. Phys., 1993, 98, 5648-5655.

54. Y. Zhao and D. Truhlar, Theor. Chem. Acc., 2008, 120, 215-241.

55. A. D. McLean and G. S. Chandler, J. Chem. Phys., 1980, 72, 56395648.

56. J. Tomasi, B. Mennucci and R. Cammi, Chem. Rev., 2005, 105, 2999-3093.

57. G. Scalmani and M. J. Frisch, J. Chem. Phys., 2010, 132, 114110114115.

58. C. Peng and H. B. Schlegel, Isr. J. Chem., 1994, 33, 449-454.

59. C. Peng, P. Y. Ayala, H. B. Schlegel and M. J. Frisch, J. Comp. Chem., 1996, 17, 49-56.

60. M. J. Frisch, G. W. Trucks, H. B. Schlegel, G. E. Scuseria, M. A. Robb, J. R. Cheeseman, G. Scalmani, V. Barone, B. Mennucci, G. A. Petersson, H. Nakatsuji, M. Caricato, X. Li, H. P. Hratchian, A. F. Izmaylov, J. Bloino, G. Zheng, J. L. Sonnenberg, M. Hada, M. Ehara, K. Toyota, R. Fukuda, J. Hasegawa, M. Ishida, T. Nakajima, Y.
Honda, O. Kitao, H. Nakai, T. Vreven, J. A. Montgomery, J. E. Peralta, F. Ogliaro, M. Bearpark, J. J. Heyd, E. Brothers, K. N. Kudin, V. N. Staroverov, R. Kobayashi, J. Normand, K. Raghavachari, A. Rendell, J. C. Burant, S. S. Iyengar, J. Tomasi, M. Cossi, N. Rega, N. J. Millam, M. Klene, J. E. Knox, J. B. Cross, V. Bakken, C. Adamo, J. Jaramillo, R. Gomperts, R. E. Stratmann, O. Yazyev, A. J. Austin, R. Cammi, C. Pomelli, J. W. Ochterski, R. L. Martin, K. Morokuma, V. G. Zakrzewski, G. A. Voth, P. Salvador, J. J. Dannenberg, S. Dapprich, A. D. Daniels, Ö. Farkas, J. B. Foresman, J. V. Ortiz, J. Cioslowski and D. J. Fox, Gaussian 09, Rev. A.1, (2009) Gaussian, Inc., Wallingford CT.

61. L. I. Simandi and M. Jaky, J. Am. Chem. Soc., 1976, 98, 1995-1997.

62. I. Fabian and G. Gordon, Inorg. Chem., 1992, 31, 2144-2150.

63. Y. Chiang, A. J. Kresge and P. Pruszynski, J. Am. Chem. Soc., 1992, 114, 3103-3107.

64. Y. Pocker, J. E. Meany, B. J. Nist and Z. C., J. Phys. Chem., 1969, 73, 2879-2882.

65. J. Damitio, G. Smith, J. E. Meany and Y. Pocker, J. Am. Chem. Soc., 1992, 114, 3081-3087.

66. J. Kozlowski and P. Zuman, Bioelectrochemistry and Bioenergetics, 1992, 28, 43-70.

67. S. Nadupalli, N. Koorbanally and S. B. Jonnalagadda, J. Phys. Chem. $A, 2011,115,7948-7954$.

68. G. Lente, J. Kalmar, Z. Baranyai, A. Kun, I. Kek, D. Bajusz, M. Takacs, L. Veres and I. Fabian, Inorg. Chem., 2009, 48, 1763-1773. 